Original article

\title{
COGNITIVE IMPAIRMENT IN PSYCHIATRIC PATIENTS RECEIVING ELECTROCONVULSIVE THERAPY
}

\author{
Ebrahim Alijanpour ${ }^{1}$, Sussan Moudi ${ }^{2}$, Laleh Babayani ${ }^{3}$,Anjella Hamidia ${ }^{4}$, Maedeh Niazifar ${ }^{5}$, Ali Bijani ${ }^{2}$ \\ ${ }^{1}$ Department of anesthesiology, Babol University of Medical Sciences, Babol, Iran \\ ${ }^{2}$ Social Determinants of Health Research Center, Health Research Institute, Babol University of Medical Sciences, Babol, Iran \\ ${ }^{3}$ Faculty of Medicine, Babol University of Medical Sciences, Babol, Iran \\ ${ }^{4}$ Department of Psychiatry, Babol University of Medical Sciences, Babol, Iran \\ ${ }^{5}$ Department of Clinical Psychology, University of Social Welfare and Rehabilitation Sciences, Tehran, Iran
}

\begin{abstract}
Introduction: Electroconvulsive therapy (ECT) has been represented as an effective and safe treatment choice for some psychiatric disorders. This research aimed to assess cognitive impairment in psychiatric patients who receive ECT. Methods: In a three-month follow-up prospective research, all of outpatient or inpatient cases admitted in psychiatric department affiliated to Babol University of Medical Sciences, North of Iran, have been examined. Beck Depression Inventory (BDI), Mini-Mental State Examination (MMSE) and Wechsler Memory Scale-fourth edition (WMS-IV) were used for data collection. These questionnaires were filled out at baseline, on the 1st and 3rd months after ECT. Results: Fifty patients with mean age $40.3 \pm 14.3$ years were recruited in the study. Bipolar mood disorder was the most frequent psychiatric disorder (42\% of total). Depression score significantly decreased between pre-ECT time and the $3 r d$ month after ECT $(p=0.001)$. No difference in MMSE and memory score measured in two time points was found $(p>0.05)$. MMSE score decreased on the first month, however, increased on the third month. Although WMS score decreased on the first month, it had an increase on the third month and reached to a level higher compared with pre ECT time. We didn't find correlation between mean WMS scores after treatment and the ECT dose $(p>0.05)$. Conclusion: Memory and cognitive impairment following ECT persists for limited period of time. Cognitive performance will be increased in the third month to a higher level, even more than the baseline values.
\end{abstract}

Key words: cognitive impairment; memory loss; depressive disorders; electroconvulsive therapy

\section{Introduction}

E lectroconvulsive therapy (ECT) is an important nonpharmacological treatment approach in psychiatric disorders ${ }^{1}$. Continuation and maintenance ECT are considered as long term therapeutic options for patients with severe and chronic mood disorders who are not adherent or responsive to the other treatment approaches ${ }^{2,3}$. Evidences demonstrate that despite the availability of various psychopharmacological treatment choices, at least one third of the patients with major depressive disorder receiving pharmacotherapy will become treatment resistant and should be treated with other therapeutic methods such as ECT ${ }^{3}$. Effectiveness and safety of ECT to treat mental disorders have been evaluated in different studies ${ }^{4,5}$. It is estimated that annually, almost one million patients receive ECT worldwide ${ }^{6}$, but the frequency and method of applying this method in psychiatric departments in different parts of the world are different.

Based on experimental studies, mechanisms of ECT antidepressive action are explained through neuroplasticity, modulation of the neurotransmitters' levels, hormones, angiogenesis and changes in cerebral blood flow ${ }^{7}$. In addition to, different theories have been raised about the role of various neurotransmitters including serotonin, dopamine, GABA and reducing effects in beta-adrenergic receptors in action mechanism of $\mathrm{ECT}^{8,9}$. Even after the replacement of the sine-wave with the briefpulse and the ultra-brief pulse, ECT remains associated with significant cognitive impairment ${ }^{10}$. 
The common side effects which are often reported by the ECT-recipients include deficits in orientation, attention, speech fluency, executive functions and memory dysfunction which have been studied in different researches in Iran and other countries $^{6,8,11-18}$. Some studies have reported no adverse effects on memory and implicit learning, and some other reported that these complications may occur and last from hours to perhaps months in some patients ${ }^{18}$. Considering that the parameters associated with the application of this method in different regions are different, recent studies demonstrate that there is still insufficient information available to determine the extent and degree of disruption in different domains of cognitive performance in ECT recipients ${ }^{18}$.

This study aimed to evaluate cognitive impairment in psychiatric patients who received ECT.

\section{Methodology}

In this prospective research, all of outpatient or inpatient cases admitted in psychiatric department affiliated to Babol University of Medical Sciences, which were candidate to receive standard bilateral ECT throughout the period of three months over the year 2017. An informed consent to participate in this research was signed by the patients who were eligible and were willing to take part in the study. All of participants provided a written informed consent form. They have been assured that their information would be kept confidential. This research has been approved in Ethics Committee of Babol University of Medical Sciences as registration code Mubabol.rec.1393.14.

Patients with psychiatric disorders whom electroconvulsive therapy was prescribed by a psychiatrist and were interested in participating in this research were recruited. Mental retardation and previously diagnosed cognitive disorders such as dementia were considered as exclusion criteria.

Collected data included demographic characteristics (age, sex, marital status, living place, occupation and education level); past medical history of physical or mental disorders; drug and substance abuse; family history of psychiatric disorders; previous history of ECT and the time when the patient has been undertaken this method.

Beck Depression Inventory (BDI) was used to distinguish the depression-related cognitive impairment from cognitive impairment caused by ECT. This inventory is a 12 -item self-reporting questionnaire which evaluates the severity of depression in normal and psychiatric adult populations ${ }^{19}$. There are four rating scales $(0-3)$ in each question to measure the severity of depression. The patients whose scores were more than 16 have been considered for psychiatric consultation and treatment for depression. Validity and reliability of its Persian translation have been approved in previous studies ${ }^{19}$.

Mini-Mental State Examination (MMSE) ${ }^{20}$ and Wechsler Memory Scale-fourth edition (WMSIV ${ }^{21}$ were used to assess cognitive performance and memory status of the study population. MMSE examines several aspects of cognition using specific questions related to attention, orientation, memory, calculation, and language. Those patients whose score were less than 25/30 were considered to have cognitive impairment. The score of 25-30 represents no cognitive impairment, 20-25 mild, 10-20 moderate and 0-10 suggests severe cognitive impairment ${ }^{20}$. The reliability and validity of the Persian version of this test were examined in previous studies; showing the overall sensitivity and specificity of $98 \%$ and $100 \%$, respectively ${ }^{22}$.

WMS-IV is a clinical tool for assessing visual working memory, auditory and visual memory of the adults. Validity and reliability of Persian translation of this questionnaire have been evaluated and approved in $\operatorname{Iran}^{21}$. Scoring and interpretation were carried out based on the original WMS-IV manual $^{23,24}$.

These three questionnaires (BDI, MMSE and WMS) have been filled out at baseline examination, on the $1^{\text {st }}$ and $3^{\text {rd }}$ months after electroconvulsive treatment.

All of study population received ECT after initial physical examination (to assess vital signs). Electroconvulsive therapy was conducted using a Dual Graph ECT machine (Sornatics LLC Company, Germany). All of participants received standard bilateral ECT. Mean ECT dose was $85.0 \pm 23.2$ millicoulombs $(\mathrm{mC})$. The oxygen saturation was checked by pulse oximeter and noninvasive blood pressure and heart rate were monitored in these patients during the ECT administration. Sodium thiopental (Rotexmedica Company, Trittau, Germany) with a dosage of $2.5-4 \mathrm{mg} / \mathrm{kg}$ and succinyl- 
choline (Caspian Tamin Pharmaceutical Company, Rasht, Iran) with a dosage of $1.5 \mathrm{mg}$ were injected to patients and when necessary relaxation was started, ECT was performed. During the ECT sessions, we recorded the percentage of electrical flow delivered, the number of prescribed ECT sessions in each treatment course and the anesthetic drug which was used.

Data analysis was performed by SPSS 22 package; $t$-test, paired t-test, and ANOVA for repeated measures were used for data analysis with significance level of $\mathrm{p}<0.05$.

\section{Results}

Fifty patients were included in the study. The flow diagram of the participants is presented in figure 1. Mean age of the participants was $40.3 \pm 14.3$ (range of 20-81) years. Out of them, 29 (58\%) were female, more than $60 \%$ were living in urban area, 38 (76\%) had no occupation, $25(50 \%)$ had education at high school level and 24 (48\%) were married. Twenty-five persons (50\%) had at least one physical disorder and 23 (46\%) had family history of psychiatric disorders. Ten individuals (20\%) reported a history of substance abuse.

Sixteen patients (32\%) had a history of electroconvulsive treatment and 34 (68\%) did not have this history. Distribution of different psychiatric disorders in the study population is presented in figure 1 . This chart shows that bipolar mood disorder was more frequent than other psychiatric disorders.

Median of total number of prescribed ECT sessions was 8 (range of 3-15) sessions. Quantitative data (mean \pm SD of BDI, MMSE and WMS scales) in three times - before ECT, the $1^{\text {st }}$ and $3^{\text {rd }}$ months after ECT - is summarized in table 1. BDI $(\mathrm{p}<0.001)$, MMSE $(\mathrm{p}<0.001)$ and WMS score ( $\mathrm{p}$ $<0.001)$ were significantly decreased on the first month after ECT compared with preECT values. Furthermore, these values were significantly different between the first and the third month after ECT administration; BDI $(\mathrm{p}<0.001)$ decreased, but MMSE $(\mathrm{p}<0.001)$ and WMS score $(\mathrm{p}=0.004)$ increased to a higher values. Depression score significantly decreased when it was compared between before ECT and the $3^{\text {rd }}$ month after ECT ( $p$ $<0.001$ ), but no significant change was found be-
Figure 1. Flow diagram of the participants

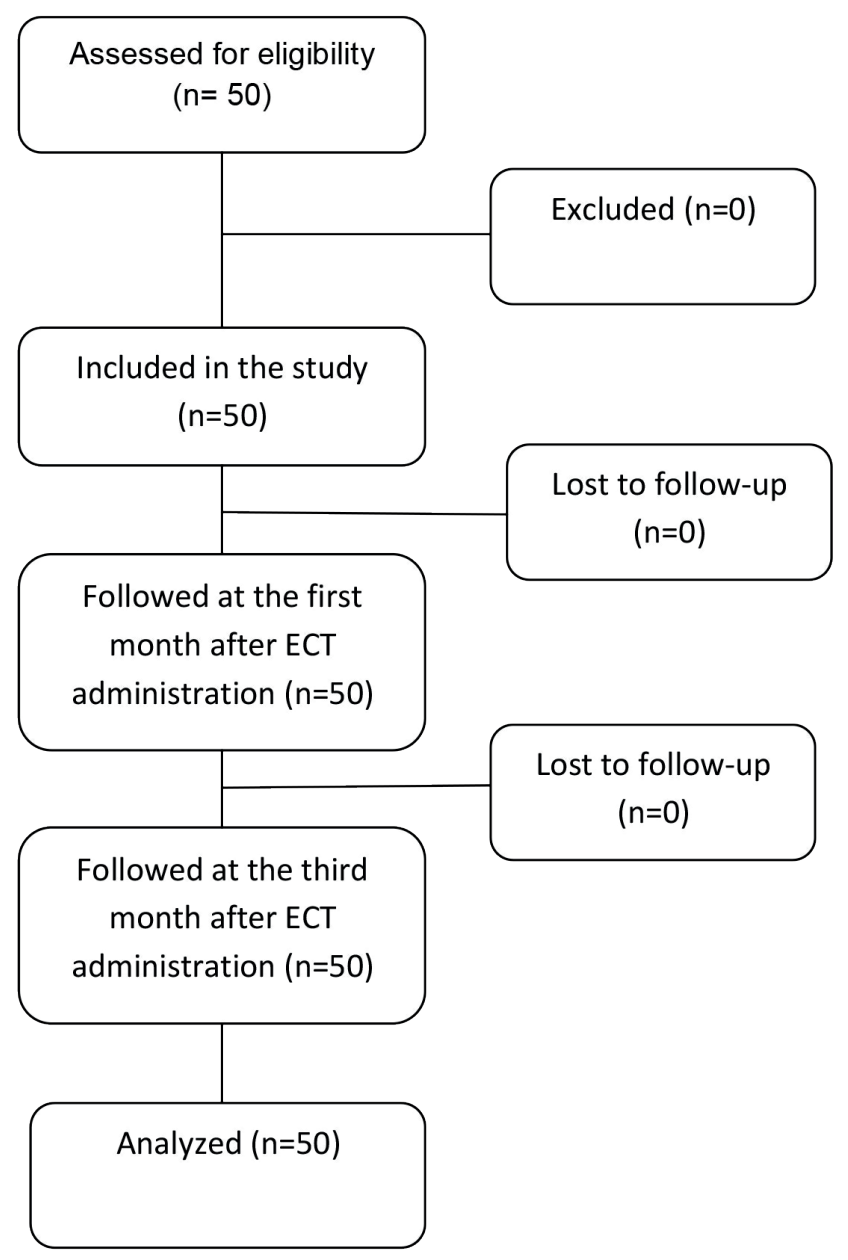

tween MMSE $(\mathrm{p}=0.12)$ and memory score $(\mathrm{p}=$ 0.20). MMSE score decreased on the first month, however, increased on the third month. Although WMS score decreased on the first month, it had an increase on the third month and reached to a level higher than before ECT.

Mean WMS score after treatment had no significant correlation with the ECT dose $(\mathrm{p}=0.534)$; furthermore, mean difference of MMSE scores before ECT administration and the first month after ECT had no significant correlation with age ( $\mathrm{p}=$ $0.378)$ and gender $(p=0.436)$. The correlation of BDI, MMSE and WMS scores with age and received electrical flow is presented in table 2. Mean of difference between [MMSE score preECT and the $3^{\text {rd }}$ month after ECT] and mean of difference between [MMSE score preECT and after the $1^{\text {st }}$ month] had significant correlation $(\mathrm{p}=0.002)$. 
Furthermore, mean of difference between [WMS first month after ECT administration, MMSE ( $\mathrm{p}=$ score preECT and the $3^{\text {rd }}$ month after ECT] and 0.14$)$ and WMS score $(p=0.78)$ had no significant mean of difference between [MMSE score preECT and the $3^{\text {rd }}$ month after ECT] had significant cordifferences between the patients whose BDI scores were $\leq 16$ and those whose scores were $>16$. Howrelation too $(\mathrm{p}=0.029)$.

ever, on the third month after ECT administration,

Table 1: $\mathrm{BDI}^{1}, \mathrm{MMSE}^{2}$ and $\mathrm{WMS}^{3}$ scores change before $\mathrm{ECT}^{4}$, the $1^{\text {st }}$ and $3^{\text {rd }}$ months after ECT

\begin{tabular}{|c|c|c|c|c|c|c|c|c|c|}
\hline \multirow{2}{*}{ Variables } & \multicolumn{3}{|c|}{$\begin{array}{c}\text { Before ECT and the first } \\
\text { month after ECT } \\
\text { mean } \pm \text { SD }\end{array}$} & \multicolumn{3}{|c|}{$\begin{array}{l}\text { Before ECT and the third } \\
\text { month after ECT } \\
\text { mean } \pm \text { SD }\end{array}$} & \multicolumn{3}{|c|}{$\begin{array}{c}\text { The first and the third month } \\
\text { after ECT } \\
\text { mean } \pm \text { SD }\end{array}$} \\
\hline & $\begin{array}{l}\text { Before } \\
\text { ECT }\end{array}$ & $\begin{array}{l}\text { The 1st } \\
\text { month } \\
\text { after } \\
\text { ECT }\end{array}$ & $\mathrm{p}$-value & $\begin{array}{l}\text { Before } \\
\text { ECT }\end{array}$ & $\begin{array}{l}\text { The 3rd } \\
\text { month } \\
\text { after } \\
\text { ECT }\end{array}$ & $\mathrm{p}$-value & $\begin{array}{l}\text { The 1st } \\
\text { month } \\
\text { after } \\
\text { ECT }\end{array}$ & $\begin{array}{l}\text { The 3rd } \\
\text { month } \\
\text { after } \\
\text { ECT }\end{array}$ & p-value \\
\hline $\begin{array}{l}\text { Beck Depression } \\
\text { Inventory score }\end{array}$ & $\begin{array}{c}29.7 \pm \\
16.0\end{array}$ & $\begin{array}{l}13.3 \pm \\
5.2\end{array}$ & $<0.001$ & $\begin{array}{c}29.7 \pm \\
16.0\end{array}$ & $\begin{array}{l}7.4 \pm \\
3.8\end{array}$ & $<0.001$ & $\begin{array}{c}13.3 \pm \\
5.2\end{array}$ & $\begin{array}{l}7.4 \pm \\
3.8\end{array}$ & $<0.001$ \\
\hline $\begin{array}{l}\text { Mini-Mental State } \\
\text { Examination score }\end{array}$ & $\begin{array}{c}22.3 \pm \\
4.6\end{array}$ & $\begin{array}{c}21.5 \pm \\
4.4\end{array}$ & $<0.001$ & $\begin{array}{c}22.3 \pm \\
4.6\end{array}$ & $\begin{array}{c}23.9 \pm \\
3.6\end{array}$ & 0.12 & $\begin{array}{c}21.5 \pm \\
4.4\end{array}$ & $\begin{array}{c}23.9 \pm \\
3.6\end{array}$ & $<0.001$ \\
\hline $\begin{array}{c}\text { Wechsler Memory } \\
\text { Scale score }\end{array}$ & $\begin{array}{l}87.0 \pm \\
16.7\end{array}$ & $\begin{array}{l}77.4 \pm \\
16.2\end{array}$ & $<0.001$ & $\begin{array}{l}87.0 \pm \\
16.7\end{array}$ & $\begin{array}{c}87.0 \pm \\
20.0\end{array}$ & 0.20 & $\begin{array}{l}77.4 \pm \\
16.2\end{array}$ & $\begin{array}{c}87.0 \pm \\
20.0\end{array}$ & 0.004 \\
\hline
\end{tabular}

1-BDI= Beck Depression Inventory; 2- MMSE= Mini-Mental State Examination; 3-WMS= Wechsler Memory Scale; 4- ECT= Electroconvulsive therapy

Figure 2. Percentage of different psychiatric disorders in the candidates for ECT

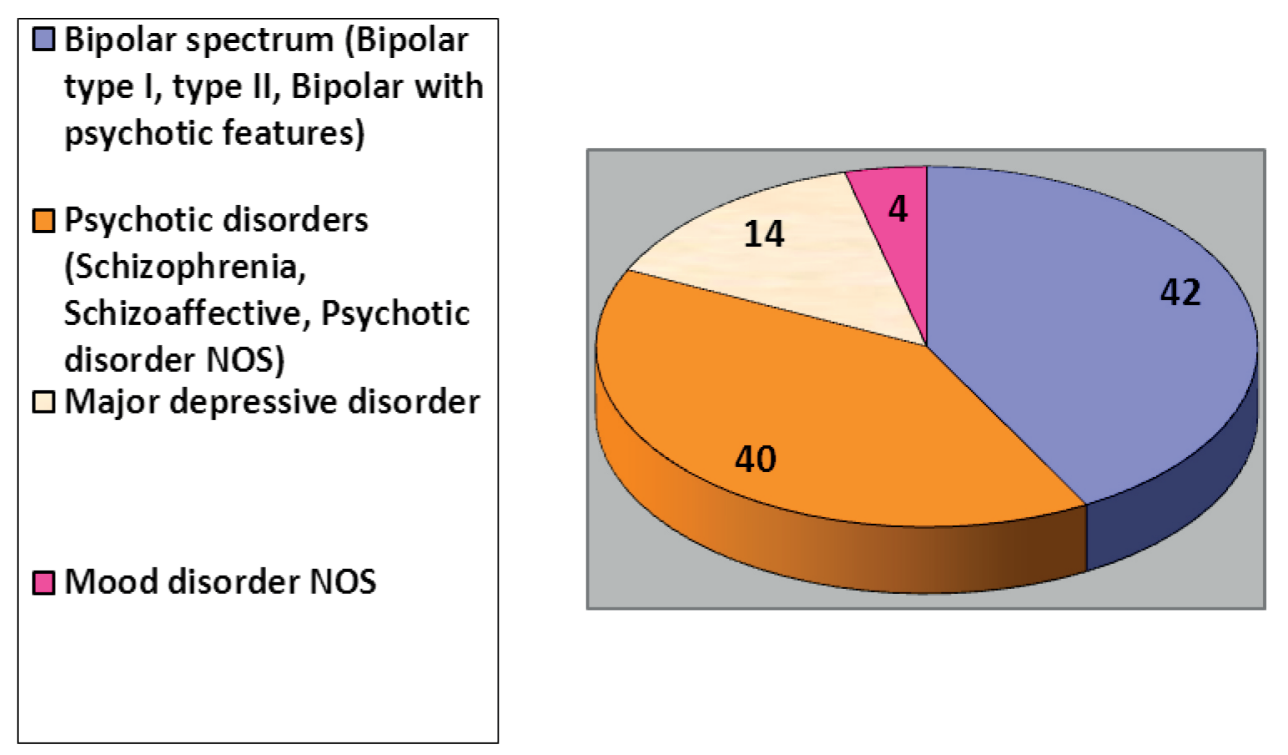

No significant association was observed between the administration of anesthetic drugs (benzodiazepines or anticholinergic drugs) and MMSE and WMS scores - measured in the preECT and the first and the third months after ECT ( $p>0.05)$.

MMSE and WMS scores were compared between the patients whose BDI scores were $\leq 16$ and those whose scores were $>16$ (table 3). On the
MMSE score had significant difference $(p=0.03$ ) but WMS had no statistical significant difference $(\mathrm{p}=0.12)$ between these two groups. 
Table 2. Correlation of $\mathrm{BDI}^{1}, \mathrm{MMSE}^{2}$ and $\mathrm{WMS}^{3}$ scores with age, gender and received electrical flow

\begin{tabular}{|c|c|c|c|c|c|c|c|c|}
\hline Age & $\begin{array}{c}r \\
p \text {-value }\end{array}$ & 1 & & & & & & \\
\hline $\begin{array}{l}\text { Delivered } \\
\text { electrical } \\
\text { flow }\end{array}$ & $\begin{array}{c}r \\
\text { p-value }\end{array}$ & $\begin{array}{l}0.094 \\
0.534\end{array}$ & 1 & & & & & \\
\hline $\begin{array}{c}\text { Total } \\
\text { number of } \\
\text { ECT sessions }\end{array}$ & $\underset{\mathrm{p}}{\mathrm{p} \text {-value }}$ & $\begin{array}{c}-0.212 \\
0.158\end{array}$ & $\begin{array}{l}0.417 \\
0.004\end{array}$ & 1 & & & & \\
\hline $\begin{array}{l}\text { Mean of } \\
\text { difference } \\
\text { between } \\
\text { MMSE score } \\
\text { before ECT } \\
\text { and the } 1^{\text {st }} \\
\text { month }\end{array}$ & $\underset{\mathrm{r}}{\mathrm{p} \text {-value }}$ & $\begin{array}{l}0.136 \\
0.378\end{array}$ & $\begin{array}{l}0.122 \\
0.436\end{array}$ & $\begin{array}{l}0.109 \\
0.485\end{array}$ & 1 & & & \\
\hline $\begin{array}{l}\text { Mean of } \\
\text { difference } \\
\text { between } \\
\text { MMSE score } \\
\text { before ECT } \\
\text { and the } 3^{\text {rd }} \\
\text { month }\end{array}$ & $\underset{\mathrm{r}}{\mathrm{p} \text {-value }}$ & $\begin{array}{c}-0.024 \\
0.896\end{array}$ & $\begin{array}{c}-0.087 \\
0.630\end{array}$ & $\begin{array}{c}-0.089 \\
0.629\end{array}$ & $\begin{array}{l}0.514 \\
0.002\end{array}$ & 1 & & \\
\hline $\begin{array}{l}\text { Mean of } \\
\text { difference } \\
\text { between } \\
\text { WMS score } \\
\text { before ECT } \\
\text { and the } 1^{\text {st }} \\
\text { month }\end{array}$ & $\begin{array}{c}r \\
\text { p-value }\end{array}$ & $\begin{array}{l}0.108 \\
0.486\end{array}$ & $\begin{array}{c}-0.043 \\
0.782\end{array}$ & $\begin{array}{l}0.069 \\
0.659\end{array}$ & $\begin{array}{l}0.016 \\
0.919\end{array}$ & $\begin{array}{l}0.280 \\
0.115\end{array}$ & 1 & \\
\hline \multirow{2}{*}{$\begin{array}{l}\text { Mean of } \\
\text { difference } \\
\text { between } \\
\text { WMS score } \\
\text { before ECT } \\
\text { and the } 3^{\text {rd }} \\
\text { month }\end{array}$} & $\stackrel{r}{\mathrm{r}}$-value & $\begin{array}{l}0.176 \\
0.335\end{array}$ & $\begin{array}{c}-0.007 \\
0.971\end{array}$ & $\begin{array}{c}-0.239 \\
0.188\end{array}$ & $\begin{array}{l}0.046 \\
0.800\end{array}$ & $\begin{array}{l}0.380 \\
0.029\end{array}$ & $\begin{array}{l}0.225 \\
0.207\end{array}$ & 1 \\
\hline & & Age & $\begin{array}{l}\text { Delivered } \\
\text { electrical } \\
\text { flow }\end{array}$ & $\begin{array}{c}\text { Total } \\
\text { number } \\
\text { of ECT } \\
\text { sessions }\end{array}$ & $\begin{array}{c}\text { Mean of } \\
\text { difference } \\
\text { between MMSE } \\
\text { score before } \\
\text { ECT and the } 1^{\text {st }} \\
\text { month }\end{array}$ & $\begin{array}{c}\text { Mean of } \\
\text { difference } \\
\text { between MMSE } \\
\text { score before } \\
\text { ECT and the } 3^{\text {rd }} \\
\text { month }\end{array}$ & $\begin{array}{l}\text { Mean of } \\
\text { difference } \\
\text { between } \\
\text { WMS score } \\
\text { before ECT } \\
\text { and the } 1^{\text {st }} \\
\text { month }\end{array}$ & $\begin{array}{c}\text { Mean of } \\
\text { difference } \\
\text { between WMS } \\
\text { score before } \\
\text { ECT and the } \\
3^{\text {rd } \text { month }}\end{array}$ \\
\hline
\end{tabular}

1-BDI= Beck Depression Inventory; 2- MMSE= Mini-Mental State Examination; 3-WMS= Wechsler Memory Scale 
Table 3. $\mathrm{MMSE}^{1}$ and $\mathrm{WMS}^{2}$ scores according to the severity of depression in $\mathrm{ECT}^{3}$ recipients

\begin{tabular}{|c|c|c|c|c|}
\hline Variables & Time & $\begin{array}{c}\text { the patients whose } \\
\text { BDI scores were } \leq 16 \\
\text { Mean } \pm \text { SD }\end{array}$ & $\begin{array}{c}\text { the patients whose } \\
\text { BDI scores were }>16 \\
\text { Mean } \pm \text { SD }\end{array}$ & $\mathrm{p}$-value \\
\hline \multirow{3}{*}{ MMSE score } & $\begin{array}{l}\text { Before ECT } \\
\text { administration }\end{array}$ & $21.1 \pm 3.3$ & $22.7 \pm 4.9$ & 0.29 \\
\hline & $\begin{array}{l}\text { The first month after } \\
\text { ECT administration }\end{array}$ & $19.8 \pm 3.4$ & $22.0 \pm 4.6$ & 0.14 \\
\hline & $\begin{array}{l}\text { The third month after } \\
\text { administration }\end{array}$ & $21.9 \pm 2.8$ & $24.8 \pm 3.6$ & 0.03 \\
\hline \multirow{3}{*}{ WMS score } & $\begin{array}{l}\text { Before ECT } \\
\text { administration }\end{array}$ & $82.3 \pm 18.8$ & $88.5 \pm 16.0$ & 0.27 \\
\hline & $\begin{array}{l}\text { The first month after } \\
\text { ECT administration }\end{array}$ & $76.2 \pm 19.0$ & $77.8 \pm 15.5$ & 0.78 \\
\hline & $\begin{array}{l}\text { The third month after } \\
\text { administration }\end{array}$ & $78.9 \pm 28.6$ & $90.5 \pm 14.4$ & 0.12 \\
\hline
\end{tabular}

1- MMSE= Mini-Mental State Examination; 2-WMS= Wechsler Memory Scale; 3- ECT= Electroconvulsive therapy

\section{Discussion}

Three months follow-up of the patient receiving ECT, revealed that although the severity of depression was decreased significantly in the first and third months after ECT, cognitive performance decreased in the first month, but increased in the third month to a higher level, even more than the baseline values. Furthermore, WMS scores decreased in the first month, but increased in the $3^{\text {rd }}$ month and reached the baseline values.

Previous studies provide different information about the degree of cognitive impairment experienced during and after ECT. This may be attributed to the subjective nature of patient reports and/ or the inflexibility of the tests which are administered to measure the cognitive performance of the patients ${ }^{25}$. Getty reported that ECT might be associated with a variety of transient impairments in cognitive performance during and following the treatment such as deficits in orientation, short term memory function, attention, speech fluency and executive functions ${ }^{18}$. These side effects could lead to limited use of ECT as an acute treatment choice for treatment-resistant depression. He mentioned that some studies reported absence of any effects on memory and implicit learning, and some others had shown diverse negative impacts on various domains of cognition ${ }^{18}$. Considering that cognitive function might impair or improve after ECT in major depressive disorder receiving this treatment procedure, Mohn monitored these patients for six months and concluded that the cognitive improvement which was observed at six-week follow-up was still maintained and even increased ${ }^{16}$. Dunn suggests that ECT techniques, baseline cognitive status and the patient's age can be associated with cognitive side effects of $\mathrm{ECT}^{26}$. Haghighi followed 38 patients with bipolar I disorder undergoing ECT for two years and reported that a better baseline cognitive performance might be associated to better cognitive status at follow-up phase ${ }^{27}$. In our research, the extent of cognitive function on the third month after ECT administration was higher in the patients who had worse baseline depressive conditions; in this group MMSE score had significant increase. This may be attributable to depression-related cognitive impairment at baseline measurement; after ECT administration and improvement in depressive condition, cognitive performance was improved. Similar to the above situation, in the patients with worse depressive condition, compared to the patients whose scores were less than 16, memory function was extended with a higher value, although the difference was not significant.

In this study, WMS score after treatment had no significant correlation with the dose of ECT, and this is in concordance with Lisanby et al re$\operatorname{search}^{28}$. Kerner et al explained that the ECT ef- 
ficacy depends of stimulus dosage and induction of seizure ${ }^{10}$. He represented that the combination of anatomical positioning of electrode placement and stimulus dose could determine the clinical efficacy and remission rate, ranging from 20 to $80^{10}$. McClintock studied multiple factors that were thought to be associated with neurocognitive effects of ECT. He reported that unilateral temporal electrode positioning could have less side effects than bilateral placement. He represented that bifrontal electrode placement had less effects on memory functions than bitemporal or right unilateral; furthermore, he compared the impact of different ECT techniques on cognitive function, memory, processing speed and attention ${ }^{29}$.

In our study, MMSE scores had no significant correlation with age and gender. However, there are some questions about the sensitivity of MMSE in evaluation of cognitive impairment related to ECT. Tornton represented the insensitivity of current measures being used to examine cognitive function during ECT and suggested to implement more sensitive measures ${ }^{30}$. McClintock reported that age was significantly associated with change in memory performance. He mentioned that cerebrovascular disease was associated with a wide range of neurocognitive disorders including dementia and cognitive impairment, in addition to, cerebrovascular disease could be associated with depression in older adults ${ }^{29}$. Getty found that ECT did not alter cognitive performance in assessed domains including speed of processing, executive function, and visual search during two hours after receiving therapy. In addition to, patients who received longer seizure duration elicited by ECT did not exhibit greater concentration impairment ${ }^{18}$.

The most important limitations of this study are conducting the research in a small population of ECT recipients and a relatively short follow-up duration; in addition to, it is recommended for future researches to consider the impacts of electroconvulsive therapy in any particular psychiatric disorder, specifically.

\section{Conclusion}

Memory and cognitive impairment following ECT were present for the limited period of time. Cognitive performance will be increased in the third month to a higher level, even more than the baseline values.

\section{Acknowledgement}

This study has been approved in Babol University of Medical Sciences as registration code 2687. Hereby, the financial support of the Vice-Chancellor for Research and Technology of Babol University of Medical Sciences is greatly appreciated.

\section{References:}

1. Slade EP, Jahn DR, Regenold WT, Case BG. Association of Electroconvulsive Therapy With Psychiatric Readmissions in US Hospitals. JAMA Psychiatry. 2017; 74(8):798-804.

2. Post T, Kemmler G, Krassnig T, Brugger A, Hausmann A. Efficacy of continuation and maintenance electroconvulsive therapy (c/m ECT) in the treatment of patients with therapy-resistant affective disorders: a retrospective analysis. Neuropsychiatr. 2015; 29(3):133-8.

3. Oremus C, Oremus M, McNeely $\mathrm{H}$, et al. Effects of electroconvulsive therapy on cognitive functioning in patients with depression: protocol for a systematic review and meta-analysis. BMJ Open. 2015; 5(3):e006966.

4. Lima NN, Nascimento VB, Peixoto JA, Moreira MM, Neto ML, Almeida JC, et al. Electroconvulsive therapy use in adolescents: a systematic review. Annals of general psychiatry. $2013 ; 12(1): 17-24$.

5. Chanpattana W, Kramer BA. Electroconvulsive therapy practice in Thailand. J ECT. 2004; 20(2):94-8.

6. Leiknes KA, Jarosh-von Schweder L, Høie B. Contemporary use and practice of electroconvulsive therapy worldwide. Brain and Behavior. 2012; 2(3):283-344.

7. Rotheneichner P, Lange S, O'Sullivan A, Marschallinger J, Zaunmair P, Geretsegger C, Aigner L, Couillard-Despres S. Hippocampal Neurogenesis and Antidepressive Therapy: Shocking Relations. Neural Plasticity. 2014: 2014, Article ID 723915. Available from: https://doi. org/10.1155/2014/723915.

8. Sadock B, Sadock V, Ruiz P, editors. Compehensive text book of psychiatry. $9^{\text {th }}$ edition ed: LWW; 2013.

9. Payne NA, Prudic J. Electroconvulsive Therapy Part I: A Perspective on the Evolution and Current Practice of ECT. Journal of psychiatric practice. 2009; 15(5):346-68.

10. Kerner N, Prudic J. Current electroconvulsive therapy practice and research in the geriatric population. Neuropsychiatry. 2014; 4(1):33-54.

11. Hojjati H, Sharifnia SH, Mobasheri M, Akhoondzadeh G. The Effect of Education Related to Electroconvulsive Therapy (ECT) on Cognitive Status of Neuropsychological Patients in Panje Azar Hospital in Gorgan. jgbfnm. 2012; 9(1):16-23.

12. Plakiotis C, Chin LF, O'Connor DW. Are reports of cognitive testing among older electroconvulsive therapy recipients clinically valid? J ECT. 2014; 30(1):26-9.

13. Martin DM, Katalinic N, Ingram A, Schweitzer I, Smith DJ, Hadzi-Pavlovic D, et al. A new early cognitive 
screening measure to detect cognitive side-effects of electroconvulsive therapy? Journal of psychiatric research. 2013; 47(12):1967-74.

14. Sedighinejad A, Nabi BN, Haghighi M, Farzam A, Sayyah Z, Kabiri M, Soleimani R, Alavi CE. Electroconvulsive therapy-related cognitive impairment and choice of anesthesia: the tipping point. J ECT. 2015; 31(2):101-4.

15. Hausner L, Damian M, Sartorius A, Frölich L. Efficacy and cognitive side effects of electroconvulsive therapy (ECT) in depressed elderly inpatients with coexisting mild cognitive impairment or dementia. J Clin Psychiatry. 2011; 72(1):91-7.

16. Mohn C, Rund BR. Maintained Improvement of Neurocognitive Function in Major Depressive Disorders 6 Months after ECT. Front Psychiatry. 2016(7):200.

17. Boere E, Kamperman AM, van 't Hoog AE, van den Broek WW, Birkenhäger TK. Anterograde Amnesia during Electroconvulsive Therapy: A Prospective Pilot-Study in Patients with Major Depressive Disorder. PLoS One. 2016; 11(10):e0165392.

18. Getty SS, Faziola LR. Adverse effects of electroconvulsive therapy on cognitive performance. Getty SS, Faziola LR Adverse effects of electroconvulsive therapy on cognitive performance Mental Illness 2017; 9(2):7181.

19. Dobson Kate, S Mohammad Khani P. Psychometric Co-ordinates of Beck Depression Inventory in patients with major depressive disorder in Relative Age. Rehabilitation 2007; 8 (Special Issue Number (29 $9^{\text {th }}$ Edition)):80-6 [in Persian].

20. Malekian N, Hosseini SR, Moudi S, Bayani MA, Kheirkhah F, Bijani A, Khalilipour A. Type 2 Diabetes Mellitus and Cognitive Function in Elderly People. Iran J Psychiatry Behav Sci. 2018: e9494.

21. Orangi M, Atef Vahid MK, Ashayeri H. Standardization of the Revised Wechsler Memory Scale in Shiraz. Journal of Psychiatry and Clinical Psychology (Thought and Behavior) 2002; 7(4):56-66 [ in Persian] Available From: http:// ijpcp.iums.ac.ir/article-1-257-en.pdf.

22. Ansari NN, Naghdi S, Hasson S, Valizadeh L, Jalaie S. Validation of a Mini-Mental State Examination (MMSE) for the Persian population: a pilot study. Appl Neuropsychol. 2010; 17(3):190-5.
23. Hoelzle JB, Nelson NW, Smoth CA. Comparison of Wechsler Memory Scale-Fourth Edition (WMS-IV) and Third Edition (WMS-III) dimensional structures: Improved ability to evaluate auditory and visual constructs. Marquette University, Psychology Faculty Research and Publications. 2011; Available from: https://pdfs.semanticscholar.org.

24. Mohagheghi A, Arfaie A, Amiri S, Nouri M, Abdi S, Safikhanlou S. Preventive Effect of Liothyronine on Electroconvulsive Therapy-Induced Memory Deficit in Patients with Major Depressive Disorder: A Double-Blind Controlled Clinical Trial. BioMed Research International. 2015; 2015:503918.

25. Müller HHO Reike M, Grosse-Holz S, et al. Electroconvulsive Therapy Hasn't Negative Effects on Short-Term Memory Function, as Assessed Using a Bedside Hand-Held Device. Mental Illness. 2017; 9(1):7093.

26. Dunn C. Cognitive Side Effects of Electroconvulsive Therapy Association of neuropsychological students and trainees. 2016 (1/25/2016). Available from: https://www.div40-anst.com/anst-blog/cognitive-side-effects-of-electroconvulsive-therapy.

27. Haghighi M, Barikani R, Jahangard L, Ahmadpanah M. Levels of mania and cognitive performance two years after ECT in patients with bipolar I disorder - results from a follow-up study. Compr Psychiatry. 2016(69):71-7.

28. Lisanby SH, Maddox JH, Prudic J, Devanand D, Sackeim HA. The effects of electroconvulsive therapy on memory of autobiographical and public events. Archives of general psychiatry. Archives of general psychiatry. 2000; 57(6):581-90.

29. McClintock SM, Choi J, Deng Z-D, Appelbaum LG, Krystal AD, Lisanby SH. Multifactorial Determinants of the Neurocognitive Effects of Electroconvulsive Therapy. The journal of ECT. 2014; 30(2):165-76.

30. Thornton A, Leathem J, Flett R. Cognitive Assessment during a Course of Electroconvulsive Therapy - A National Questionnaire Survey of Current Practice in Aotearoa, New Zealand. New Zealand Journal of Psychology. 2014; 43(2):14-19. 